Article

\title{
Understanding the Mechanism of the Intramolecular Stetter Reaction. A DFT Study
}

\section{Luis R. Domingo *, Ramón J. Zaragozá, Jose A. Saéz and Manuel Arnó}

Departamento de Química Orgánica, Universidad de Valencia, Dr. Moliner 50, E-46100 Burjassot, Valencia, Spain

* Author to whom correspondence should be addressed; E-Mail: domingo@utopia.uv.es; Tel.: +34-963-543-106; Fax: +34-963-544-328.

Received: 22 December 2011; in revised form: 19 January 2012 / Accepted: 20 January 2012 / Published: 2 February 2012

\begin{abstract}
The mechanism of the $N$-heterocyclic carbene (NHC)-catalyzed intramolecular Stetter reaction of salicylaldehyde $\mathbf{1}$ to yield chromanone $\mathbf{3}$ has been theoretically studied at the B3LYP/6-31G** level. This NHC-catalyzed reaction takes place through six elementary steps, which involve: (i) formation of the Breslow intermediate IN2; (ii) an intramolecular Michael-Type addition in IN2 to form the new C-C $\sigma$ bond; and (iii) extrusion of the NHC catalyst from the Michael adduct to yield chromanone 3. Analysis of the relative free energies in toluene indicates that while formation of Breslow intermediate IN2 involves the rate-determining step of the catalytic process, the intramolecular Michaeltype addition is the stereoselectivity determining step responsible for the configuration of the stereogenic carbon $\alpha$ to the carbonyl of chromanone 3. An ELF analysis at TSs and intermediates involved in the Michael-type addition allows for the characterization of the electronic changes along the $\mathrm{C}-\mathrm{C}$ bond-formation.
\end{abstract}

Keywords: organocatalysis; $N$-heterocyclic carbenes; umpolung reactivity; intramolecular Stetter reaction; intramolecular Michael addition; mechanisms; DFT calculations

\section{Introduction}

The umpolung reactivity of aldehydes promoted by $N$-heterocyclic carbenes (NHCs) constitutes an important class of organocatalysis and has found a broad range of applications in synthetic organic chemistry [1-6]. The corresponding acyl anions or equivalent homoenolate intermediates are able to 
attack nucleophilically various electrophiles, such as aldehydes [7-9], ketones [10-18], imines [19-22], and even activated polarized $\mathrm{C}=\mathrm{C}$ double bonds $[23,24]$.

The latter class of reaction is especially interesting, since it permits the umpolung $\mathrm{C}-\mathrm{C}$ coupling between aldehydes and an appropriate Michael acceptor. In the Stetter reaction, originally conceived in the 1970's, a homoenolate or Breslow intermediate, which inverts the normal reactivity mode of an aldehyde, provokes a Michael-type addition to electrophilically activated $\mathrm{C}=\mathrm{C}$ double bonds (see Scheme 1) [25-27].

Scheme 1. NHC-catalyzed intermolecular Stetter reaction.

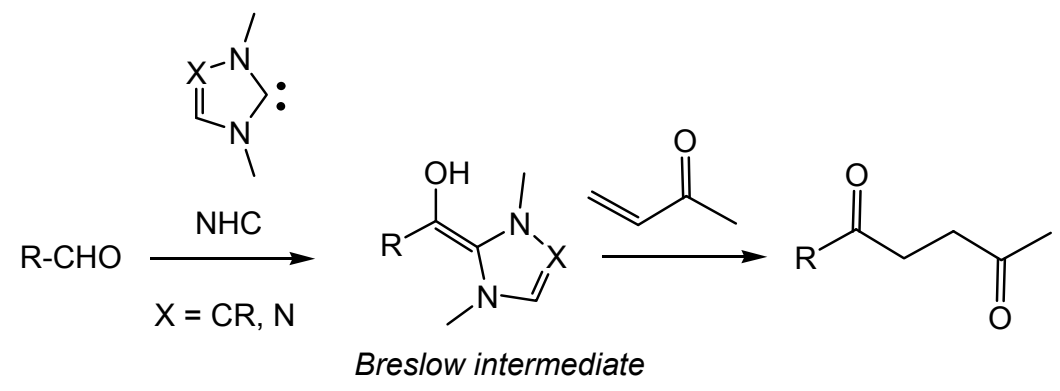

Enders and co-workers were the first to report an asymmetric intramolecular Stetter reaction in 1996 [28]. Using chiral triazolium salt 2, chromanone 3 was obtained in moderate yield (73\%) and enantioselectivity $(60 \%$ ee) (see Scheme 2$)$. Despite the moderate selectivity, the implementation of chiral triazolinylidene carbenes in the asymmetric Stetter reaction laid the foundation for future works. Hence, Rovis performed an extensive study to improve yield and enantioselectivity in asymmetric intramolecular Stetter reactions using more efficient chiral triazolium salts, different salicylaldehyde derivatives and various reaction conditions [29-33].

Scheme 2. NHC-catalyzed intramolecular Stetter reaction of salicylaldehyde 1.

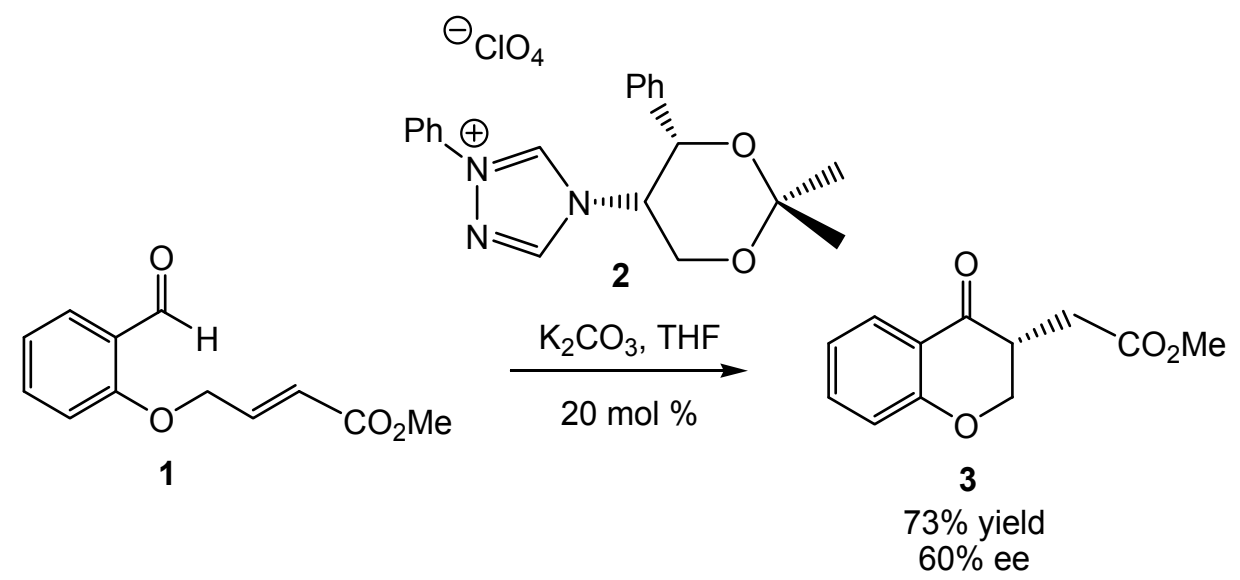

Very recently, You et al. [34] reported the synthesis of some $(1 R, 2 R)$-DPEN-derived triazolium salts such as 5, which favor the intramolecular Stetter reaction with excellent yields and stereoselectivities of up to $97 \%$ ee (see Scheme 3). Several conventional bases were used, $\mathrm{NEt}_{3}$ being optimal in terms of both yield and ee of the product [34]. Solvents such as xylene, $\mathrm{CH}_{2} \mathrm{Cl}_{2}, \mathrm{THF}, \mathrm{Et}_{2} \mathrm{O}$ and toluene were tested, but xylene led to an optimal combination of $95 \%$ yield and $93 \%$ ee [34]. 
Scheme 3. NHC-catalyzed intramolecular Stetter reaction of salicylaldehyde 4.

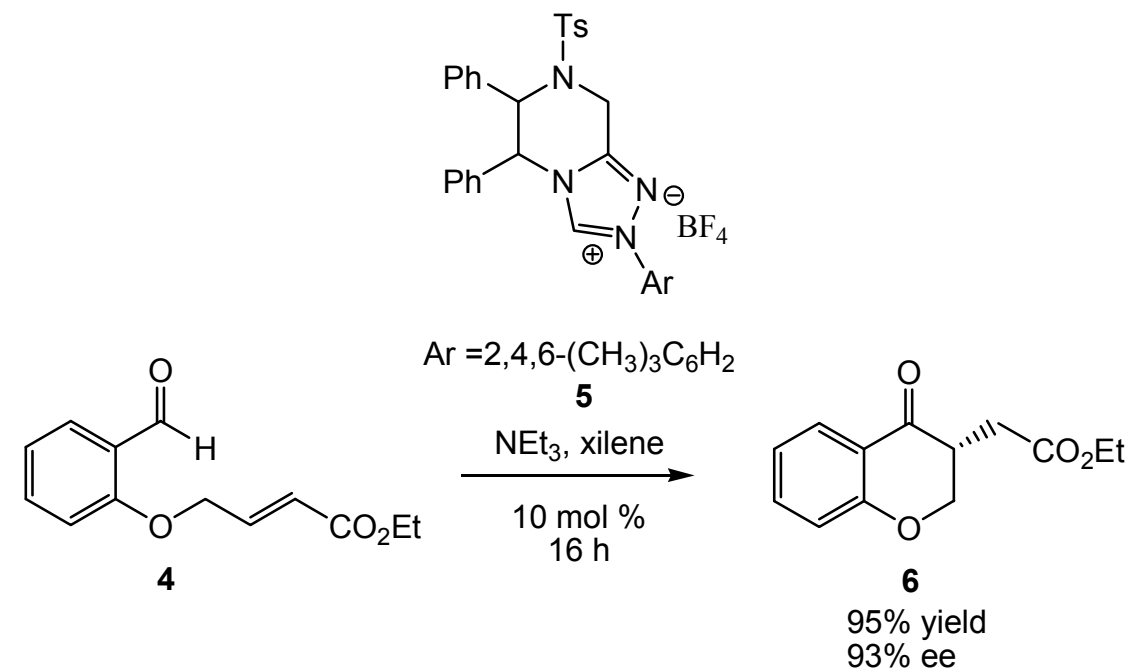

Substitution effects on the aromatic ring of the salicylaldehyde structure and the nature of the tether have been analyzed. Thus, substrates bearing electron-donating groups in the salicylaldehyde structure are well tolerated and lead to their corresponding chromanone derivatives in good to excellent yields (87\%-98\%) and generally high ees (88\%-97\%). However, the presence of electron-withdrawing groups provide the corresponding chromanone derivatives with good yields but with relatively low ees [34]. Moreover, the use of oxygen, sulfur, nitrogen and carbon linkers, and the incorporation of various tethered Michael acceptors including amides, esters, thioesters, ketones, aldehydes and nitriles do not modify substantially yields and/or enantioselectivities [32]. The proposed catalytic cycle for the intermolecular Stetter reaction is shown in Scheme 4.

Scheme 4. Proposed catalytic cycle for the intermolecular Stetter reaction.

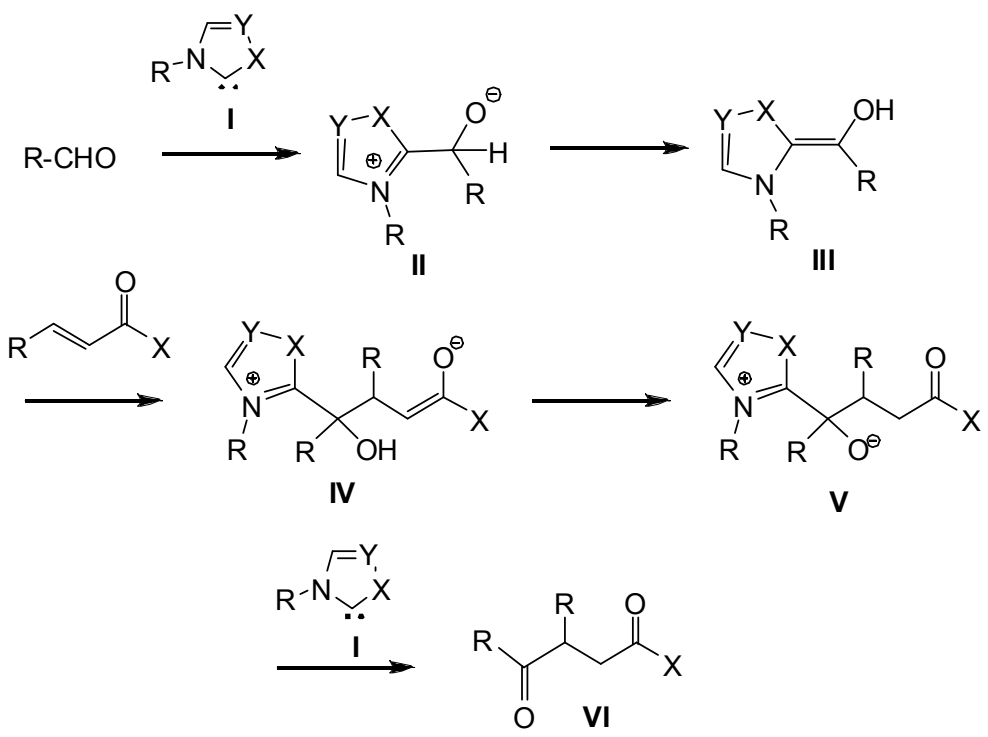

NHC I, formed in situ by base deprotonation of the corresponding azolium salt, adds to the aldehyde to form the zwitterionic intermediate II. A proton transfer process generates Breslow intermediate III. Subsequent intermolecular addition to the Michael acceptor moiety forms the new 
C-C $\sigma$ bond to generate intermediate IV, which by a hydrogen transfer process provides $\mathbf{V}$. Finally, extrusion of the NHC catalyst $\mathbf{I}$ from the tetrahedral intermediate $\mathbf{V}$ affords the Stetter product VI.

Very recently, Rovis reported an experimental mechanistic investigation of the enantioselective intramolecular Stetter reaction, finding that the proton transfer from tetrahedral intermediate II, formed upon nucleophilic attack of the carbene on the aldehyde to yield Breslow intermediate III, is the first irreversible step [35].

The intermolecular Stetter reaction has been theoretically studied [36-38]. Very recently, Houk et al. studied the effect of catalyst fluorination in asymmetric Stetter reactions (see Scheme 5) [38]. They found that the more favorable transition state strucutures (TSs) associated with the Michael-type addition of the corresponding Breslow intermediate to the $\beta$-conjugated position of nitroalkene $\mathbf{8}$ exhibited a stabilizing interaction between the Breslow hydroxyl hydrogen and the carbon in the $\alpha$-position to the nitro group of $\mathbf{8}$. Note that the hydrogen-bond (HB) does not only catalyze the addition by an increase of the electrophilic character of nitroalkene $\mathbf{8}$, but also favors the stereoselective addition in a single step.

Scheme 5. NHC-catalyzed intermolecular Stetter reaction of nitroalkene $\mathbf{8}$.

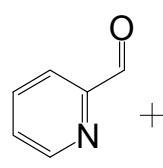

7<smiles>O=[N+]([O-])C=C[GeH2]</smiles>

8<smiles></smiles>

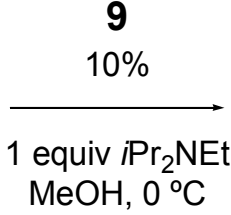

MeOH, $0^{\circ} \mathrm{C}$<smiles>O=C(c1ccccn1)C(CCl)C[N+](=O)[O-]</smiles>

10

$95 \%$ yield $95 \%$ ee

Our interest in organocatalysis, more specifically in the participation of NHCs as catalysts in the umpolung reactivity of aldehydes, prompted us to perform some theoretical studies on the molecular mechanisms of these reactions [39-41]. In the present manuscript, we report a DFT study of the molecular mechanism of the intramolecular Stetter reaction of salicylaldehyde $\mathbf{1}$ to yield $(R)$-chromanone 3 (see Scheme 6). An ELF analysis of the electron reorganization along the intramolecular Michael-type addition is performed in order to understand the $\mathrm{C}-\mathrm{C}$ bond-formation step.

Scheme 6. Reaction model of the NHC-catalyzed intramolecular Stetter reaction of salicylaldehyde $\mathbf{1 .}$

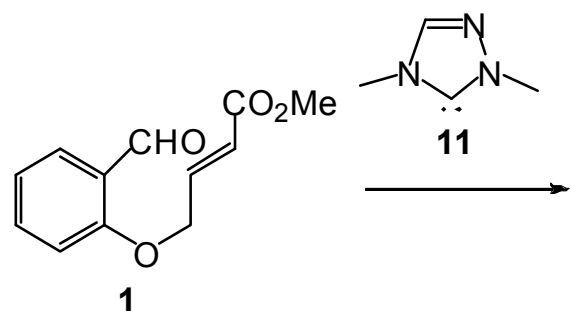

1<smiles>CC(=O)CC1COc2ccccc2C1=O</smiles>

3 


\section{Computational Methods}

DFT calculations were carried out using B3LYP $[42,43]$ exchange-correlation functionals, together with the standard 6-31G** basis set [44]. Optimizations were performed using the Berny analytical gradient optimization method [45,46]. The stationary points were characterized by frequency calculations in order to verify that TSs had one and only one imaginary frequency. The intrinsic reaction coordinate (IRC) [47] paths were traced in order to check the energy profiles connecting each TS to the two associated minima of the proposed mechanism using the second order González-Schlegel integration method $[48,49]$. Values of free energies in toluene were calculated with the standard statistical thermodynamics at $298.15 \mathrm{~K}$ and $1 \mathrm{~atm}$ over the optimized gas phase structures [44]. Toluene solvent effects were considered by single point energy calculations using a self-consistent reaction field (SCRF) [50,51] based on the polarizable continuum model (PCM) of Tomasi's group [52-54]. The UFF radii model was used to generate the molecular cavity in PCM calculations. The electronic structures of stationary points were analyzed by the natural bond orbital (NBO) method $[55,56]$ and by the topological analysis of the ELF, $\eta(\mathbf{r})$ [57-59]. The ELF study was performed with the TopMod program [60] using the corresponding monodeterminantal wavefunctions of the selected structures of the IRC. All calculations were carried out with the Gaussian 03 suite of programs [61].

The global electrophilicity index [62], $\omega$, is given by the following simple expression, $\omega=\left(\mu^{2} / 2 \eta\right)$, in terms of the electronic chemical potential $\mu$ and the chemical hardness $\eta$. Both quantities may be approached in terms of the one electron energies of the frontier molecular orbital HOMO and LUMO, $\varepsilon_{\mathrm{H}}$ and $\varepsilon_{\mathrm{L}}$, as $\mu \approx\left(\varepsilon_{\mathrm{H}}+\varepsilon_{\mathrm{L}}\right) / 2$ and $\eta \approx\left(\varepsilon_{\mathrm{L}}-\varepsilon_{\mathrm{H}}\right)$, respectively [63]. Recently, we have introduced an empirical (relative) nucleophilicity index, $\mathrm{N}[64,65]$, based on the HOMO energies obtained within the Kohn-Sham scheme [66], and defined as $\mathrm{N}=\mathrm{E}_{\mathrm{HOMO}(\mathrm{Nu})}-\mathrm{E}_{\mathrm{HOMO}(\mathrm{TCE})}$. The nucleophilicity is referred to tetracyanoethylene (TCE), because it presents the lowest HOMO energy in a large series of investigated molecules. This choice allows for the convenient handling of a nucleophilicity scale of positive values [64]. Local electrophilicity [67] and nucleophilicity [68] indices, $\omega_{\mathrm{k}}$ and $\mathrm{N}_{\mathrm{k}}$, were evaluated using the following expressions: $\omega_{k}=\omega f_{k}^{+}$and $N_{k}=N f_{k}^{-}$where $f_{k}^{+}$and $f_{k}^{-}$are the Fukui functions [69] for nucleophilic and electrophilic attacks, respectively [70].

Very recently, we proposed a local reactivity difference index $R_{k}$ [71] able to predict the local electrophilic and/or nucleophilic activation within an organic molecule, which is defined as [71]:

$$
\begin{aligned}
& \text { if }\left(1<\omega_{\mathrm{k}} / \mathrm{N}_{\mathrm{k}}<2\right) \text { or }\left(1<\mathrm{N}_{\mathrm{k}} / \omega_{\mathrm{k}}<2\right) \\
& \text { then } \mathrm{R}_{\mathrm{k}} \approx\left(\omega_{\mathrm{k}}+\mathrm{N}_{\mathrm{k}}\right) / 2 \quad \Rightarrow \quad \text { ambiphilic }\left(\mathrm{R}_{\mathrm{k}}= \pm \mathrm{n} . \mathrm{nn}\right) \\
& \text { else } \mathrm{R}_{\mathrm{k}} \approx\left(\omega_{\mathrm{k}}-\mathrm{N}_{\mathrm{k}}\right) \\
& \text { where } \mathrm{R}_{\mathrm{k}}>0 \quad \Rightarrow \quad \text { electrophilic }\left(\mathrm{R}_{\mathrm{k}}=+\mathrm{n} . \mathrm{nn}\right) \\
& \text { and } \mathrm{R}_{\mathrm{k}}<0 \quad \Rightarrow \quad \text { nucleophilic }(\mathrm{Rk}=-\mathrm{n} . \mathrm{nn}) \\
& \text { if }\left|R_{k}\right|<0.10, \quad \text { then } \quad R_{k}=0.00
\end{aligned}
$$

In the $\mathrm{R}_{\mathrm{k}}$ index, the sign $(+,-, \pm$ ) indicates the electrophilic or/and nucleophilic character of the center $\mathrm{k}$, while the magnitude n.nn provides a measure of the local activation [71]. 


\section{Results and Discussion}

The study of the NHC-catalyzed intramolecular Stetter reaction of salicylaldehyde $\mathbf{1}$ to yield $(R)$-chromanone 3 has been divided into three parts: (i) energy and geometrical analysis of stationary points involved in the intramolecular Stetter reaction; (ii) analysis of the reaction based on DFT reactivity indices; and (iii) ELF topology analysis of the bonding along the intramolecular Michael-type addition of Breslow intermediate IN2.

\subsection{Energy and Geometrical Analysis of Stationary Points Involved in the Intramolecular Stetter}

Reaction of Salicylaldehyde 1

The NHC-catalyzed intramolecular Stetter reaction of salicylaldehyde $\mathbf{1}$ to yield chromanone $\mathbf{3}$ comprises several elementary steps (see Scheme 7). The first one is the nucleophilic attack of NHC 11 on the carbonyl C3 carbon of salicylaldehyde 1 to yield the zwitterionic intermediate IN1, which by a proton transfer affords Breslow intermediate IN2. The subsequent intramolecular Michael-type addition to the conjugated $\mathrm{C} 4$ carbon of intermediate IN2 yields ol-enolate IN3r, which experiences a hydrogen transfer to afford alcohoxy intermediate IN4r. Finally, extrusion of NHC catalyst 11 from IN4r provides chromanone 3. The relative enthalpies and free energies in toluene associated with this NHC-catalyzed reaction are given in Table 1, while a schematic representation of the energy profile is shown in Figure 1. The energy discussion will be made on the basis of solvent free energies in toluene.

Scheme 7. Reaction mechanism of the intramolecular Stetter reaction.<smiles>CCOc1ccccc1OCCO</smiles>

1

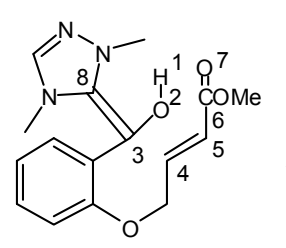

IN2
TS1<smiles></smiles>

11

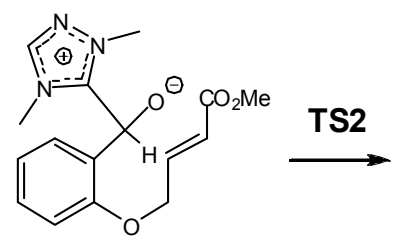

IN1
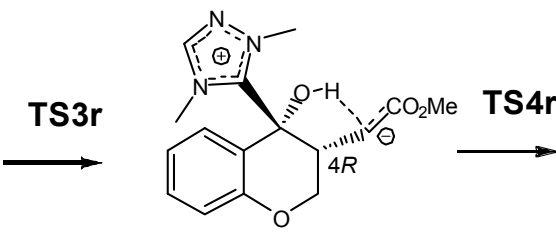

IN3r<smiles>CC(=O)C[C@H]1COc2ccccc2[C@@]1(O)c1n(C)nc[n+]1C</smiles>

IN4r

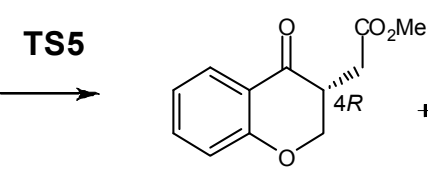

3

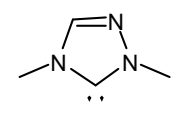

11 
Table 1. Total ( $\mathrm{H}$ and $\mathrm{G}$, in au) and relative $(\Delta \mathrm{H}$ and $\Delta \mathrm{G}$, in $\mathrm{kcal} / \mathrm{mol})$ enthalpies and free energies, computed at $25{ }^{\circ} \mathrm{C}$ and $1 \mathrm{~atm}$ in toluene, of the stationary points involved in the intramolecular Stetter reaction of salicylaldehyde 1.

\begin{tabular}{lrrrr}
\hline & $\mathbf{H}$ & $\Delta \mathbf{H}$ & $\mathbf{G}$ & \multicolumn{1}{c}{$\Delta \mathbf{G}$} \\
\hline $\mathbf{1}$ & -765.154909 & & -765.216688 & \\
$\mathbf{1 1}$ & -320.722503 & & -320.761367 & \\
TS1 & -1085.864102 & 8.4 & -1085.943426 & 21.7 \\
IN1 & -1085.875090 & 1.5 & -1085.953173 & 15.6 \\
TS2 & -1085.807807 & 43.7 & -1085.885314 & 58.2 \\
IN2 & -1085.879507 & -1.3 & -1085.957544 & 12.9 \\
TS3r & -1085.873415 & 2.5 & -1085.944874 & 20.8 \\
IN3r & -1085.884019 & -4.1 & -1085.955978 & 13.9 \\
TS3s & -1085.870106 & 4.6 & -085.941886 & 22.7 \\
IN3s & -1085.884133 & -4.2 & -1085.954410 & 14.8 \\
TS4r & -1085.885839 & -5.3 & -1085.956900 & 13.3 \\
IN4r & -1085.900792 & -14.7 & -1085.973665 & 2.8 \\
IN4s & -1085.878805 & -0.9 & -1085.949454 & 17.9 \\
TS5 & -1085.896768 & -12.1 & -1085.970371 & 4.8 \\
$\mathbf{3}$ & -765.194373 & -24.8 & -765.251292 & -21.7 \\
\hline
\end{tabular}

Figure 1. Free energy profile, in $\mathrm{kcal} / \mathrm{mol}$, of the stationary points involved in the NHC-catalyzed intramolecular Stetter reaction of salicylaldehyde 1. Relative free energies of TS21 and IN12 are respect IN11.

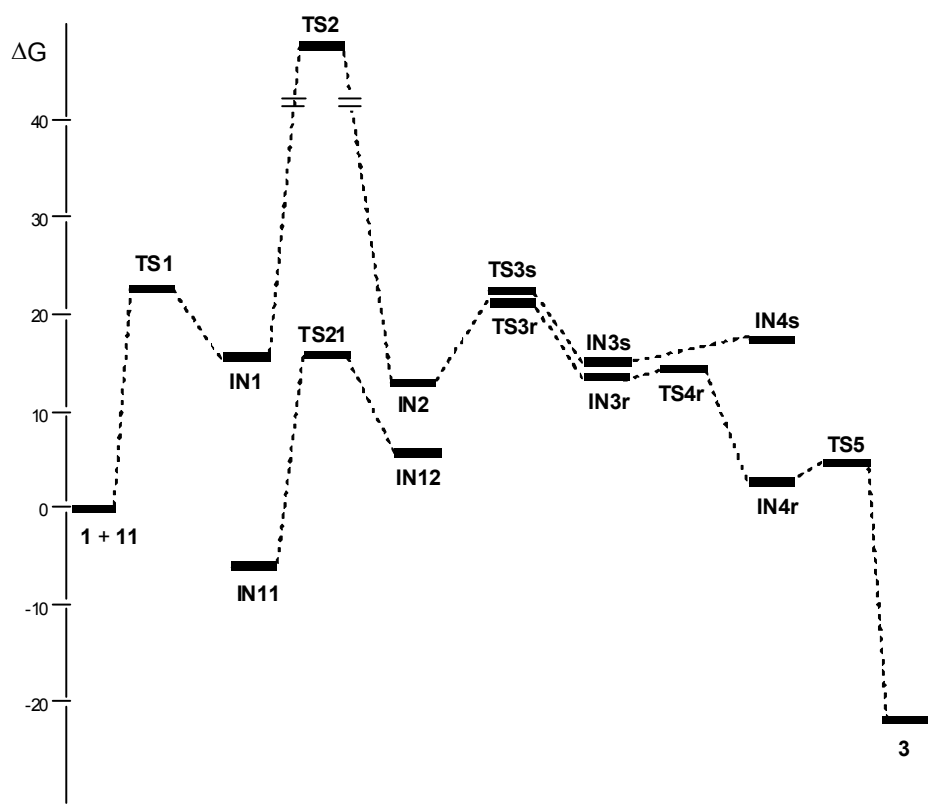

TS1, associated with the nucleophilic attack of the C8 carbon of NHC 11 on the $\mathrm{C} 3$ carbon of salicylaldehyde 1, presents a free activation energy of $21.7 \mathrm{kcal} / \mathrm{mol}$; formation of the zwitterionic intermediate IN1 is endergonic by $15.6 \mathrm{kcal} / \mathrm{mol}$. The subsequent proton transfer from the aldehyde $\mathrm{C} 3$ carbon to the $\mathrm{O} 2$ oxygen at the zwitterionic intermediate IN1 affords Breslow intermediate IN2. Recently, we have shown that direct proton transfer with formation of Breslow intermediates such as 
IN2 have a very high free activation energy as a consequence of the strain associated with the threemembered TSs [39,41]; accordingly, the free activation energy associated with the proton transfer via TS2 is very high, $42.6 \mathrm{kcal} / \mathrm{mol}$. Several acid/base species can catalyzed the conversion of zwitterionic intermediate IN1 into Breslow intermediate IN2 [39,41], including the $\mathrm{NEt}_{3} / \mathrm{NEt}_{3} \mathrm{H}^{+}$pair resulting from the deprotonation of the triazolium salts [34]. We tested this possibility in order to estimate the free activation energy associated with the proton transfer. Since the unsaturated ester appendage present in salicylaldehyde 1 does not participate in this process, we used a reduced model in which the unsaturated ester present in IN1 was replaced by a methyl group (see Scheme 8, relative free energies in toluene are given in parentheses). The intermolecular hydrogen transfer process takes place in two steps: (i) protonation of the alcohoxy $\mathrm{O} 2$ oxygen by triethyl ammonium cation; and (ii) abstraction of the H1 hydrogen by triethylamine. The first step is barrierless and strongly exothermic due to the more basic character of the alcohoxy $\mathrm{O} 2$ oxygen than triethylamine. However, the subsequent $\mathrm{H} 1$ hydrogen abstraction has an appreciable activation free energy; $21.4 \mathrm{kcal} / \mathrm{mol}$ from IN11 plus NEt 3 . Therefore, this energy barrier, which is similar to those found in formation of Breslow intermediates catalyzed by methanol [39,41], indicates that the proton transfer is the rate-determining step in formation of Breslow intermediate IN2. From 1 plus 11, formation of Breslow intermediate IN2 is endergonic by $12.9 \mathrm{kcal} / \mathrm{mol}$.

Scheme 8. Intermolecular hydrogen abstraction associated with the formation of Breslow intermediates.

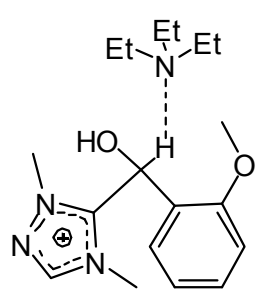

IN11

$(0.0)$
TS21

$(21.4)$

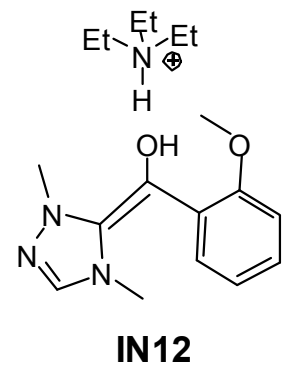

(12.5)

The next step is the intramolecular nucleophilic attack of the $\mathrm{C} 3$ carbon belonging to the Breslow framework on the conjugated $\mathrm{C} 4$ carbon of the unsaturated ester framework present in IN2 to yield the ol-enolate IN3r. For the intramolecular Michael-type addition, which is the stereoselectivity determining step responsible for the $R$ or $S$ configuration at the stereogenic carbon $\alpha$ to the carbonyl carbon of chromanone $\mathbf{3}$, four stereoisomeric channels related to the nucleophilic attack of the re- or si-face of the C3 carbon of the Breslow framework of IN2 on the re- or si-face of the conjugated C4 carbon of the unsaturated ester residue are feasible. In experimental Breslow intermediates, both the nucleophilic $\mathrm{C} 3$ carbon and the electrophilic $\mathrm{C} 4$ carbon are prochiral centers. As the $\mathrm{C} 8$ environment at NHC 11 is symmetric, this NHC cannot induce diastereoselectivity and then, only the two stereoisomeric channels associated with the attack of the si-face of the C3 carbon of the Breslow framework on the re- or si-face of the conjugated $\mathrm{C} 4$ carbon of the unsaturated ester residue were considered (see Scheme 9). Consequently, two TSs, TS3r and TS3s, and the corresponding Michael zwitterionic intermediates IN3r and IN3s, allowing for the $R$ and $S$ configuration at the stereogenic 
carbon $\alpha$ to the carbonyl carbon of chromanone 3, were studied (see Scheme 9). From Breslow intermediate IN2, the free activation energies associated with TS3r and TS3s are 7.9 and $9.8 \mathrm{kcal} / \mathrm{mol}$, respectively. Formation of Michael intermediates IN3r and IN3s is endergonic by 1.0 and $1.9 \mathrm{kcal} / \mathrm{mol}$. The free energy difference between TS3r and TS3s, $1.9 \mathrm{kcal} / \mathrm{mol}$, may be attributed to the preferential HB formation to the C5 carbon of the enolate at TS3r rather than to the O7 oxygen atom at TS3s. Further study using a more complex NHC model would be needed to disclose the stereoselectivity origin. IN3r, with negative free activation energy, $-0.5 \mathrm{kcal} / \mathrm{mol}$, experiences a fast hydrogen transfer process via TS4r to yield the Michael adduct IN4r. From Breslow intermediate IN2, formation of IN4r is strongly exergonic, $-10.1 \mathrm{kcal} / \mathrm{mol}$. This behavior makes the $\mathrm{C} 3-\mathrm{C} 4$ bond-formation step irreversible. All attempts to obtain enolester IN4s as a stationary point were unsuccessful as it reverts to IN3s. Restricted optimization of IN4s fixing the O7-H1 distance yields a species which is $3.1 \mathrm{kcal}$ above IN3s. Finally, intermediate IN4r experiences an easy extrusion of NHC catalyst 11 to yield chromanone 3, through a low free activation energy process, $2.0 \mathrm{kcal} / \mathrm{mol}$, via TS5. From the separated reagents, 1 plus 11, formation of chromanone 3 is strongly exergonic, $-21.7 \mathrm{kcal} / \mathrm{mol}$.

Scheme 9. Competitive channels associated with the intramolecular Michael addition in IN2.

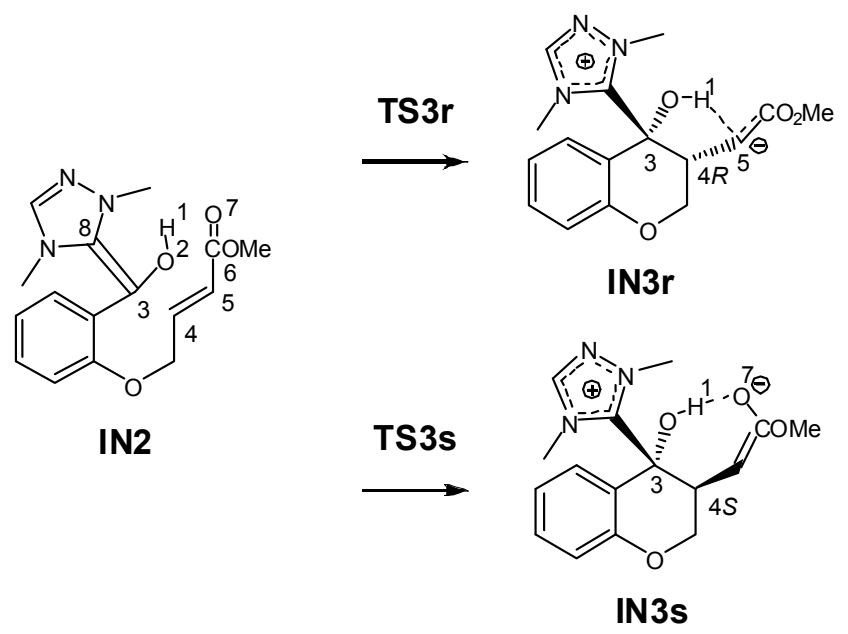

Analysis of the free energy profile given in Figure 1 shows that while formation of Breslow intermediate IN2 is endergonic, formation of Michael-type adduct IN4r, and chromanone 3, from IN2 and IN4r, are exergonic processes. As the proton transfer in IN1 is the most unfavorable step, formation of Breslow intermediate IN2 is the rate-determining step. This behavior is in agreement with Rovis's recent proposal that the proton transfer from tetrahedral intermediate IN1 is the first irreversible step [35]. On the other hand, once IN2 is formed, the reaction progresses irreversibly. The lower free energy found at TS4r than at TS3r together with the irreversible character of the intramolecular Michael-type addition prompts the nucleophilic attack of the $\mathrm{C} 3$ carbon on the electrophilic C4 carbon of IN2 via TS3r, the stereoselectivity determining step responsible for the configuration of stereogenic carbon $\alpha$ to the carbonyl carbon of chromanone 3 .

The gas-phase geometries of the TSs involved in the NHC-catalyzed intramolecular Stetter reaction are given in Figure 2. At TS1, associated with the nucleophilic attack of the C8 carbon of NHC catalyst 11 on the carbonyl $\mathrm{C} 3$ carbon of salicylaldehyde 1, the length of the $\mathrm{C} 3-\mathrm{C} 8$ forming bond is $1.856 \AA$. At TS2, associated with the intramolecular proton transfer process, the lengths of the $\mathrm{C} 3-\mathrm{H} 1$ 
breaking and O2-H1 forming-bond are 1.184 $\AA$ and 1.326 $\AA$, respectively. At the stereoisomeric TSs associated with the intramolecular Michael-type addition of the Breslow framework to the $\beta$-conjugated position of the unsaturated ester framework of IN2, the lengths of the $\mathrm{C} 3-\mathrm{C} 4$ forming bonds are $2.126 \AA$ (TS3r) and $2.044 \AA$ (TS3s). While at TS3r the distance between the hydroxyl H1 hydrogen and the C5 carbon of the unsaturated ester is $1.874 \AA$, at TS3s the distance between the hydroxyl H1 hydrogen and the carboxyl $\mathrm{O} 7$ oxygen is $1.790 \AA$. These short distances point to strong HB interactions as a consequence of the negative charge that is being transferred towards the unsaturated ester framework. At TS4r, associated with the intramolecular hydrogen transfer process, the lengths of the O2-H1 breaking and $\mathrm{C} 5-\mathrm{H} 1$ forming bonds are $1.133 \AA$ and $1.524 \AA$, respectively. These values indicate that the TS has an early character. At TS5 associated with the extrusion of NHC catalyst 11, the length of the C3-C8 breaking bond is $1.922 \AA$. Finally, at TS21 associated with the hydrogen elimination in intermediate IN11, the lengths of the $\mathrm{C} 3-\mathrm{H} 1$ breaking- and $\mathrm{N} 1-\mathrm{H}$ forming-bonds are $1.544 \AA$ and $1.255 \AA$, respectively.

Figure 2. Transition structures associated with the NHC-catalyzed intramolecular Stetter reaction of salicylaldehyde $\mathbf{1}$. The distances are given in $\AA$.

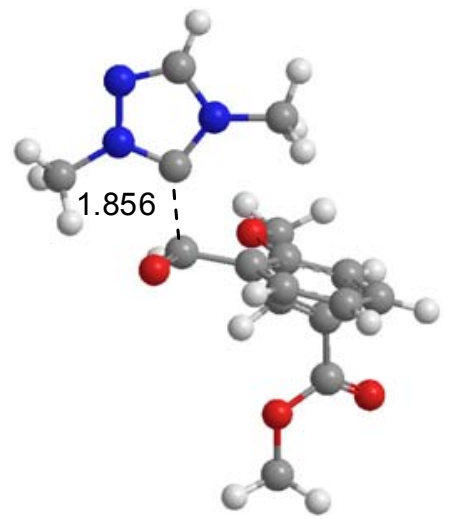

TS1

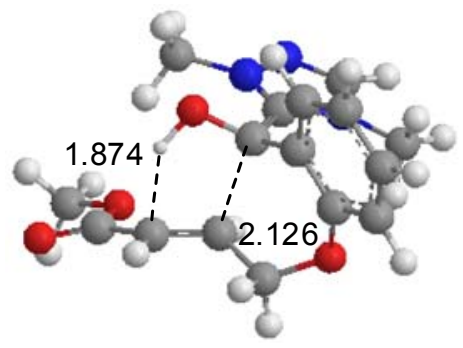

TS3r

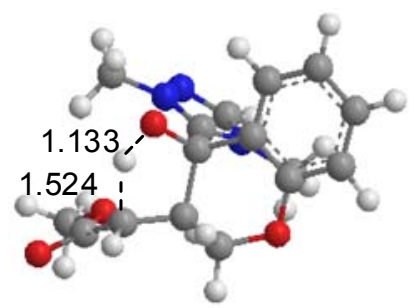

TS4r

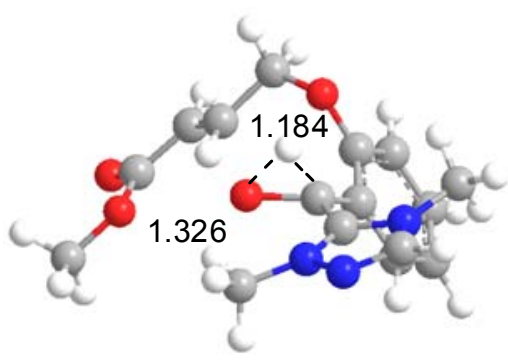

TS2

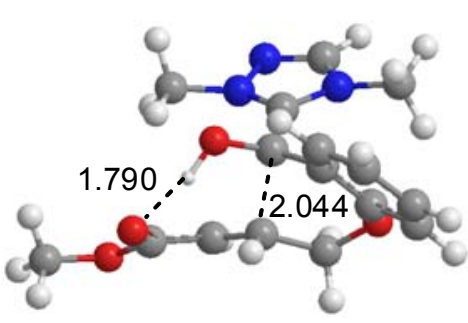

TS3s

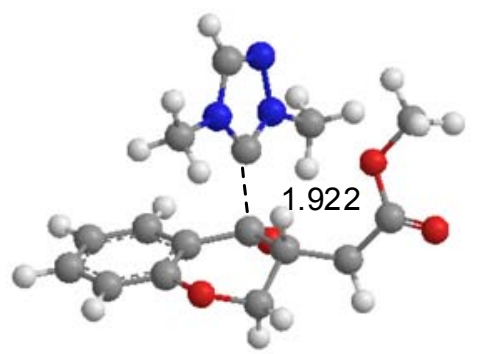

TS5 


\subsection{Analysis of the Reaction Based on DFT Reactivity Indices}

Analysis of the reactivity indices defined within the conceptual DFT allows for the understanding of polar reactions. The static global properties of the species involved in the nucleophilic/electrophilic interactions along the NHC-catalyzed intramolecular Stetter reaction of salicylaldehyde 1, namely electronic chemical potential $(\mu)$, chemical hardness $(\eta)$, global electrophilicity $(\omega)$, and global nucleophilicity $(\mathrm{N})$, are given in Table 2.

Table 2. Electronic chemical potential ( $\mu$, in a.u.), chemical hardness ( $\eta$, in a.u.), global electrophilicity $(\omega$, in eV), and global nucleophilicity $(\mathrm{N}$, in $\mathrm{eV})$ of salicylaldehyde $\mathbf{1}, \mathrm{NHC}$ 11 and Breslow intermediate IN2.

\begin{tabular}{lcccc}
\hline & $\boldsymbol{\mu}$ & $\boldsymbol{\eta}$ & $\boldsymbol{\omega}$ & $\mathbf{N}$ \\
\hline Benzaldehyde & -0.1590 & 0.1923 & 1.79 & 2.18 \\
$\mathbf{1}$ & -0.1503 & 0.1752 & 1.75 & 2.65 \\
Methyl acrylate & -0.1586 & 0.2267 & 1.51 & 1.72 \\
IN2 & -0.0975 & 0.0974 & 1.33 & 5.14 \\
$\mathbf{1 1}$ & -0.0964 & 0.2334 & 0.54 & 3.32 \\
\hline
\end{tabular}

Salicylaldehyde 1 has an electrophilicity power of $1.75 \mathrm{eV}$, which is closer to that of benzaldehyde, $\omega=1.79 \mathrm{eV}$, therefore, both are classified as strong electrophiles within the electrophilicity scale [72]. Salicylaldehyde 1 has a nucleophilicity index $\mathrm{N}$ of $2.67 \mathrm{eV}$, being classified as a moderate nucleophile [73]. On the other hand, NHC 11 has a low electrophilicity index, $\omega=0.54 \mathrm{eV}$, being classified as a marginal electrophile, while it is a strong nucleophile, $\mathrm{N}=3.32 \mathrm{eV}$ [39]. Consequently, it is expected that along the nucleophilic attack of NHC $\mathbf{1 1}$ on salicylaldehyde $\mathbf{1}$ there will be a strong nucleophile/electrophile interaction, favoring the formation of tetrahedral intermediate IN1.

Recent studies devoted to intramolecular Diels-Alder reactions have shown that the analysis of the global electrophilicity and nucleophilicity indices at the ground state of reagents is able to predict the polar character of these intramolecular reactions [74,75]. The electrophilicity of Breslow intermediate IN2, $\omega=1.33 \mathrm{eV}$, allows for its classification as a moderate electrophile. Note that the electrophilicity of IN2 is closer to that of methyl acrylate $\omega=1.51 \mathrm{eV}$; On the other hand, IN2 has a high nucleophilicity index of $5.14 \mathrm{eV}$, thus being classified as a strong nucleophile. Consequently, it is expected that the intramolecular Michael-type addition in IN2 will take place through a strong nucleophile/electrophile electronic interaction, which will favor a polar process. Note that the electrophilicity of intermediate IN2 is increased through the formation of intramolecular HBs of the H1 hydrogen with the C5 carbon or O7 oxygen along the intramolecular Michael-type addition (see Scheme 8).

Recently, we have proposed a local reactivity difference index $\mathrm{R}_{\mathrm{k}}$ able to predict the local electrophilic and/or nucleophilic activation within an organic molecule [71].Together with the electrophilic and/or nucleophilic behavior of the $\mathrm{k}$ center, denominated by its sign, the magnitude of the $R_{k}$ index accounts for the extent of the electronic activation. The representation of the significant $\mathrm{R}_{\mathrm{k}}$ indices, $\left|\mathrm{R}_{\mathrm{k}}\right|>0.10 \mathrm{eV}$, in a molecule constitutes the $\mathrm{R}_{\mathrm{k}}$ molecular map of reactivity (RMMR) [71]. The RMMRs of salicylaldehyde 1, NHC catalyst $\mathbf{1 1}$ and Breslow intermediate IN2 are given in Scheme 10. 
Scheme 10. RMMRs of salicylaldehyde 1, NHC catalyst 11 and Breslow intermediate IN2.
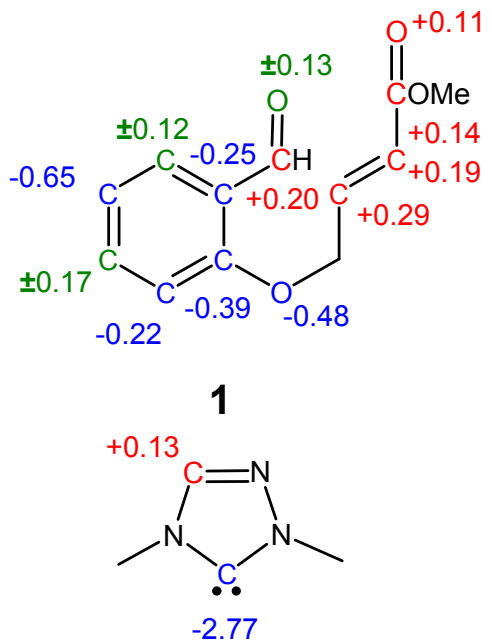

11

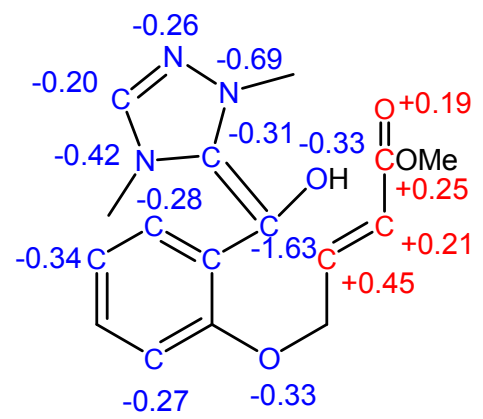

IN2

Salicylaldehyde 1 has the most electrophilically activated sites at the carbonyl $\mathrm{C} 3$ carbon, $\mathrm{R}_{\mathrm{C} 3}=+0.20 \mathrm{eV}$, and at the conjugated $\mathrm{C} 4$ carbon, $\mathrm{R}_{\mathrm{C} 4}=+0.29 \mathrm{eV}$. Althrough the $\mathrm{C} 4$ carbon is more electrophilically activated than the $\mathrm{C} 3$ one, the reversible nucleophilic attack of $\mathbf{1 1}$ at the $\mathrm{C} 4$ carbon and the irreversible nucleophilic attack at $\mathrm{C} 3$ can shift the reaction towards IN2.

The C8 carbon of NHC catalyst $\mathbf{1 1}$ is the only nucleophilically activated center of this molecule, $\mathrm{R}_{\mathrm{C} 8}=-2.77 \mathrm{eV}$, therefore concentrating most of the nucleophilicity of the NHC, N=3.32 eV. This behavior is due to the fact that most of the electron-density associated with the HOMO of NHC $\mathbf{1 1}$ is located at the $\mathrm{sp}^{2}$ hybridized $\mathrm{C} 8$ carbon.

Breslow intermediate IN2 presents nucleophilic activation at the atoms belonging to NHC and the aldehyde frameworks, while the unsaturated ester framework shows electrophilic activation (see Scheme 10). Whereas the C3 carbon belonging to the Breslow framework is the most nucleophilic center of IN2, $\mathrm{R}_{\mathrm{C} 3}=-1.63 \mathrm{eV}$, the conjugated $\mathrm{C} 4$ carbon is the most electrophilically activated center, $\mathrm{R}_{\mathrm{C} 4}=+0.45 \mathrm{eV}$. Consequently, the most favorable nucleophilic/electrophilic interaction along the intramolecular process will take place between the $\mathrm{C} 3$ and $\mathrm{C} 4$ carbons, allowing for the $\mathrm{C} 3-\mathrm{C} 4$ bond-formation. 


\subsection{ELF Bonding Analysis along the Intramolecular Michael Addition in Breslow Intermediate IN2}

Recent theoretical studies have shown that the topological analysis of the ELF along the reaction path associated with an organic reaction is a valuable tool for understanding the bonding changes along the reaction path, and therefore, to characterize the molecular mechanism [76-82].

Consequently, a topology analysis of the ELF of the stationary points involved in the intramolecular Michael-type addition in Breslow intermediate IN2 was carried out in order to characterize the bond formation. The $N$ populations of the more relevant ELF valence basins of the stationary points involved in the intramolecular Michael-type addition in Breslow intermediate IN2 are listed in Table 3, while the positions of the more relevant attractors for TS2r and TS3r are shown in Figure 3.

Table 3. Valence basin populations $N$ of the most relevant valence basins calculated from the ELF of the intramolecular Michael addition in Breslow intermediate IN2.

\begin{tabular}{lccccc}
\hline & IN2 & TS3r & IN3r & TS4r & IN4r \\
\hline V(C3,C8) & 2.01 & 2.85 & 2.45 & 2.44 & 2.44 \\
V'(C3,C8) $^{\prime}$ & 2.20 & & & & \\
V(O2) & 2.39 & 2.44 & 2.34 & 2.44 & 2.17 \\
V'(O2) $^{\prime}$ '(O2) & 2.43 & 2.47 & 2.52 & 2.57 & 3.87 \\
V(O2,C3) & 1.24 & 1.35 & 1.36 & 0.94 & \\
V(C4,C5) & 1.76 & 2.79 & 2.02 & 1.99 & 1.58 \\
V'(C4,C5) & 1.72 & & & & \\
V(C3,C4) & & 1.04 & 1.85 & 1.86 & 1.96 \\
V(C4) & & 0.34 & & & \\
V(C5) & & 0.54 & 1.17 & 1.26 & \\
V(H1,O2) & 1.71 & 1.65 & 1.61 & & \\
V(H1) & & & & 0.57 & \\
V(H1,C5) & & & & & 2.01 \\
\hline
\end{tabular}

Figure 3. Most relevant ELF attractors at TS3r and TS4r associated with the intramolecular Michael addition in Breslow intermediate IN2.

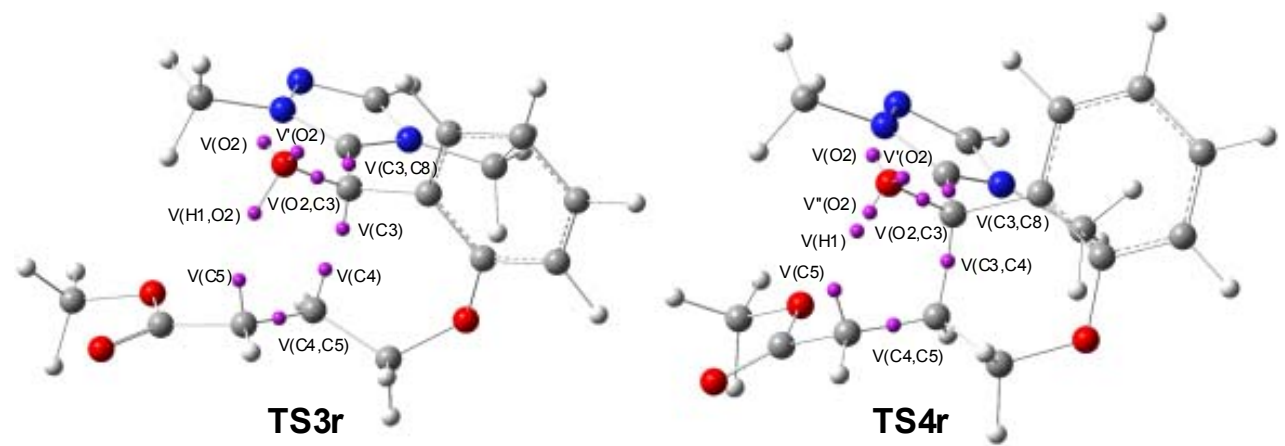

ELF analysis of Breslow intermediate IN2 shows one disynaptic basin V(H1,O2) and another disynaptic basin $\mathrm{V}(\mathrm{O} 2, \mathrm{C} 3)$, each one integrating $1.71 \mathrm{e}$ and $1.24 \mathrm{e}$, respectively, associated with the $\mathrm{O} 2-\mathrm{H} 1$ and $\mathrm{O} 2-\mathrm{C} 3 \sigma$ bonds, and two monosynaptic basins, $\mathrm{V}(\mathrm{O} 2)$ and $\mathrm{V}^{\prime}(\mathrm{O} 2)$, integrating a total of $4.82 \mathrm{e}$, which are associated with the two lone pairs of the $\mathrm{O} 2$ oxygen. The populations of these four valence basins show a strong polarization of the electron-density of the single O2-H1 and O2-C3 $\sigma$ 
bonds towards the electronegative $\mathrm{O} 2$ oxygen. Breslow intermediate IN2 also presents two pairs of disynaptic basins, $\mathrm{V}(\mathrm{C} 3, \mathrm{C} 8)$ and $\mathrm{V}^{\prime}(\mathrm{C} 3, \mathrm{C} 8)$ and $\mathrm{V}(\mathrm{C} 4, \mathrm{C} 5)$ and $\mathrm{V}^{\prime}(\mathrm{C} 4, \mathrm{C} 5)$, which integrate a total of $4.21 \mathrm{e}$ and $3.48 \mathrm{e}$, respectively, corresponding to the $\mathrm{C} 3-\mathrm{C} 8$ and $\mathrm{C} 4-\mathrm{C} 5$ double bonds present in the Lewis structure of intermediate IN2.

At TS3r, some relevant changes take place relative to the electronic structure of Breslow intermediate IN2 (see Figure 3). The two disynaptic basins $\mathrm{V}(\mathrm{C} 4, \mathrm{C} 5)$ and $\mathrm{V}^{\prime}(\mathrm{C} 4, \mathrm{C} 5)$ merge into one disynaptic basin $\mathrm{V}(\mathrm{C} 4, \mathrm{C} 5)$, which accounts for $2.79 \mathrm{e}$. Consequently, a strong reduction of the electron-density at the $\mathrm{C} 4-\mathrm{C} 5$ double bond region has taken place. Concurrently, two monosynaptic basins $\mathrm{V}(\mathrm{C} 4)$ and $\mathrm{V}(\mathrm{C} 5)$, integrating $0.34 \mathrm{e}$ and $0.54 \mathrm{e}$, respectively, emerge at the olefinic $\mathrm{C} 4$ and $\mathrm{C} 5$ carbons. Interestingly, a new disynaptic basin $\mathrm{V}(\mathrm{C} 3, \mathrm{C} 4)$, integrating $1.04 \mathrm{e}$, associated with the formation of the new $\mathrm{C} 3-\mathrm{C} 4 \sigma$ bond, appears. Consequently, the $\mathrm{C} 3-\mathrm{C} 4 \sigma$ bond is already formed at TS3r. On going from TS3r to IN4r, this disynaptic basin is fully populated. Finally, at TS3r, the two disynaptic basins $\mathrm{V}(\mathrm{C} 3, \mathrm{C} 8)$ and $\mathrm{V}^{\prime}(\mathrm{C} 3, \mathrm{C} 8)$, associated with the $\mathrm{C} 3-\mathrm{C} 8$ double bond present at intermediate IN2, also merge into one disynaptic basin $\mathrm{V}(\mathrm{C} 3, \mathrm{C} 8)$ with a population of $2.85 \mathrm{e}$.

At IN3r, while the monosynaptic basin $\mathrm{V}(\mathrm{C} 4)$ has disappeared, and the population of the disynaptic basin $\mathrm{V}(\mathrm{C} 4, \mathrm{C} 5)$ has decreased to $2.02 \mathrm{e}$, the population of the new disynaptic basin $\mathrm{V}(\mathrm{C} 3, \mathrm{C} 4)$ increases to $1.85 \mathrm{e}$, indicating that the new $\mathrm{C} 3-\mathrm{C} 4 \sigma$ bond is almost completed. On going from IN2 to IN3r, the population of the disynaptic basin $\mathrm{V}(\mathrm{H} 1, \mathrm{O} 2)$ decreases slightly to $1.61 \mathrm{e}$.

At TS4r while the disynaptic basin $\mathrm{V}(\mathrm{H} 1, \mathrm{O} 2)$ has disappeared, two new monosynaptic basins V', $(\mathrm{O} 2)$ and $\mathrm{V}(\mathrm{H} 1)$, associated with the hydrogen transfer process, with a population of $0.94 \mathrm{e}$ and $0.57 \mathrm{e}$, respectively, are created (see Figure 3). Note that these two monosynaptic basins come from the O2-H1 breaking bond. On the other hand, the population of the monosynaptic basin V(C5) amounts to 1.26e.

Finally, at IN4r, the two monosynaptic basins $\mathrm{V}(\mathrm{H} 1)$ and $\mathrm{V}(\mathrm{C} 5)$ merge into the new disynaptic basin $\mathrm{V}(\mathrm{H} 1, \mathrm{C} 5)$ with a population of 2.01e, indicating that the H1-C5 $\sigma$ bond has been completely formed.

Taking a look at the results obtained through the ELF topology analysis at the stationary points of the NHC-catalyzed intramolecular Michael-type addition, we can see that the forming and breaking bond processes take place in two differentiated steps. Along the first step, the new $\mathrm{C} 3-\mathrm{C} 4 \sigma$ bond is already created at TS3r, while the population of the corresponding disynaptic basin $\mathrm{V}(\mathrm{C} 3, \mathrm{C} 4)$ is practically completed at intermediate IN3r. At this step, the H1-O2 $\sigma$ bond remains practically unchanged. Along the second step, the $\mathrm{H} 1$ hydrogen is transferred from the $\mathrm{O} 2$ oxygen to the $\mathrm{C} 5$ carbon. This second step starts at TS4r, where the H1-O2 $\sigma$ bond is broken, yielding two new monosynaptic basins $\mathrm{V}(\mathrm{H} 1)$ and $\mathrm{V}$ ' $(\mathrm{O} 2)$, which disappear at IN4r with the formation of the second C5-H1 $\sigma$ bond.

\section{Conclusions}

The mechanism of the NHC-catalyzed intramolecular Stetter reaction of salicylaldehyde $\mathbf{1}$ to yield chromanone 3 has been theoretically studied at the B3LYP/6-31G** computational level. This NHC-catalyzed reaction takes place through six elementary steps. The reaction begins by the nucleophilic attack of the NHC catalyst on the aldehyde carbon of salicylaldehyde $\mathbf{1}$ to yield a tetrahedral intermediate, which in a two-step proton transfer process generates Breslow intermediate IN2. The subsequent intramolecular addition to the Michael acceptor moiety forms the new C-C $\sigma$ bond to generate intermediate IN3r, which by a fast hydrogen transfer process provides alcohoxy 
intermediate IN4r. Finally, extrusion of the NHC catalyst from this intermediate affords the Stetter product 3. Analysis of the free energy profile associated with this catalytic process indicates that while formation of Breslow intermediate IN2 involves the rate-determining step, the intramolecular Michael-type addition in Breslow intermediate IN2 is the stereoselectivity determining step responsible for the configuration of the stereogenic carbon $\alpha$ to the carbonyl carbon of chromanone 3 .

Analysis of the reactivity indices defined within the conceptual DFT verifies the high reactivity of Breslow intermediate IN2. Finally, an ELF bonding analysis at TSs and intermediates involved in the intramolecular Michael-type addition allows for the characterization of the bond-formation. While at TS3r the new C3-C4 $\sigma$ bond is already formed, at TS4r the hydroxyl H1 hydrogen is transferred to the olefinic C5 carbon.

\section{Acknowledgments}

This work was supported by research funds provided by the Ministerio de Ciencia e Innovación of the Spanish Government (project CTQ2009-11027 /BQU).

\section{References and Notes}

1. Nair, V.; Vellalath, S.; Babu, B.P. Recent advances in carbon-carbon bond-forming reactions involving homoenolates generated by NHC catalysis. Chem. Soc. Rev. 2008, 37, 2691-2698.

2. Enders, D.; Niemeier, O.; Henseler, A. Organocatalysis by $N$-heterocyclic carbenes. Chem. Rev. 2007, 107, 5606-5655.

3. Marion, N.; Díez-González, S.; Nolan, S.P. N-Heterocyclic carbenes as organocatalysts. Angew. Chem. Int. Ed. 2007, 46, 2988-3000.

4. Chiang, P.-C.; Bode, J.W. N-Heterocyclic carbenes as organic catalysts. In N-Heterocyclic Carbenes, Díez-González, S., Ed.; The Royal Society of Chemistry: Cambridge, UK, 2011; Chapter 14, pp. 399-435.

5. Moore, J.L.; Rovis, T. Asymmetric organocatalysis. Top. Curr. Chem. 2011, 291, 77-144.

6. Vora, H.U.; Rovis, T. Asymmetric $N$-heterocyclic carbene (NHC) catalyzed acyl anion reactions. Aldrichimica Acta 2010, 44, 3-11.

7. Enders, D.; Kallfass, U. An efficient nucleophilic carbene catalyst for the asymmetric benzoin condensation. $N$-Heterocyclic carbene-catalyzed generation of homoenolates: $\gamma$-Butyrolactones by direct annulations of enals and aldehydes. Angew. Chem. Int. Ed. 2002, 41, 1743-1745.

8. Sohn, S.S.; Rosen, E.L.; Bode, J.W. N-Heterocyclic carbene-catalyzed generation of homoenolates: $\gamma$-Butyrolactones by direct annulations of enals and aldehydes. J. Am. Chem. Soc. 2004, 126, 14370-14371.

9. Burstein, C.; Glorius, F. Organocatalyzed conjugate umpolung of $\alpha, \beta$-unsaturated aldehydes for the synthesis of $\gamma$-butyrolactones. Angew. Chem. Int. Ed. 2004, 6205-6208.

10. Hachisu, Y.; Bode, J.W.; Suzuki, K. Catalytic intramolecular crossed aldehyde-ketone benzoin reactions: A novel synthesis of functionalized preanthraquinones. J. Am. Chem. Soc. 2003, 125, 8432-8433.

11. Takikawa, H.; Suzuki, K. Modified chiral triazolium salts for enantioselective benzoin cyclization of enolizable keto-aldehydes: Synthesis of (+)-Sappanone B. Org. Lett. 2007, 9, 2713-2716. 
12. Takikawa, H.; Hachisu, Y.; Bode, J.W.; Suzuki, K. Catalytic enantioselective crossed aldehydeketone benzoin cyclization. Angew. Chem. Int. Ed. 2006, 45, 3492-3494.

13. Enders, D.; Niemeier, O.; Balensiefer, T. Asymmetric intramolecular crossed-benzoin reactions by $\mathrm{N}$-heterocyclic carbene catalysis. Angew. Chem. Int. Ed. 2006, 45, 1463-1467.

14. Burstein, C.; Tschan, S.; Xie, X.L.; Glorius, F. N-heterocyclic carbene-catalyzed conjugate umpolung for the synthesis of gamma-butyrolactones. Synthesis 2006, 2418-2439.

15. Schrader, W.; Handayani, P.P.; Burstein, C.; Glorius, F. Investigating organocatalytic reactions: Mass spectrometric studies of a conjugate umpolung reaction. Chem. Commun. 2007, 716-718.

16. Hirano, K.; Piel, I.; Glorius, F. Diastereoselective synthesis of trifluoromethylated $\gamma$-butyrolactones via $N$-heterocyclic carbene-catalyzed conjugated umpolung of $\alpha, \beta$-unsaturated aldehydes. Adv. Synth. Catal. 2008, 350, 984-988.

17. Nair, V.; Vellalath, S.; Poonoth, M.; Mohan, R.; Suresh, E. N-Heterocyclic carbene catalyzed reaction of enals and 1,2-dicarbonyl compounds: Stereoselective synthesis of spiro $\gamma$-butyrolactones. Org. Lett. 2006, 8, 507-509.

18. Chan, A.; Scheidt, K.A. Hydroacylation of activated ketones catalyzed by $N$-heterocyclic carbenes. J. Am. Chem. Soc. 2006, 128, 4558-4559.

19. Mennen, S.M.; Gipson, J.D.; Kim, Y.R.; Miller, S. Thiazolylalanine-derived catalysts for enantioselective intermolecular aldehyde-imine cross-couplings. J. Am. Chem. Soc. 2005, 127, 1654-1655.

20. Li, G.-Q.; Dai, L.-X.; You, S.-L. Thiazolium-derived carbene-catalyzed cross-coupling of aldehydes with unactivated imines. Chem. Commun. 2007, 852-854.

21. He, M.; Bode, J.W. Catalytic synthesis of $\gamma$-lactams via direct annulations of enals and $N$-sulfonylimines. Org. Lett. 2005, 7, 3131-3134.

22. Rommel, M.; Fukuzumi, T.; Bode, J.W. Cyclic ketimines as superior electrophiles for NHCcatalyzed homoenolate additions with broad scope and low catalyst loadings. J. Am. Chem. Soc. 2008, 130, 17266-17267.

23. Christmann, M. New developments in the asymmetric Stetter reaction. Angew. Chem. Int. Ed. 2005, 44, 2632-2634.

24. Read de Alaniz, J.; Rovis, T. The catalytic asymmetric intramolecular Stetter seaction. Synlett 2009, 1189-1207.

25. Stetter, H. Catalyzed addition of aldehydes to activated double bonds-A new synthetic approach. Angew. Chem. Int. Ed. Engl. 1976, 15, 639-647.

26. Stetter, H.; Schreckenberg, M. A new method for addition of aldehydes to activated double bonds. Angew. Chem. Int. Ed. Engl. 1973, 12, 81.

27. Stetter, H.; Kuhlmann, H. The catalyzed nucleophilic addition of aldehydes to electrophilic double bonds. Org. React. 1991, 40, 407-496.

28. Enders, D.; Breuer, K.; Runsink, J.; Teles, J.H. The first asymmetric intramolecular Stetter reaction. Preliminary communication. Helv. Chim. Acta 1996, 79, 1899-1902.

29. Kerr, M.S.; Read de Alaniz, J.; Rovis, T. A highly enantioselective catalytic intramolecular Stetter reaction. J. Am. Chem. Soc. 2002, 124, 10298-10299.

30. Read de Alaniz, J.; Rovis, T. A highly enantio- and diastereoselective catalytic intramolecular Stetter reaction. J. Am. Chem. Soc. 2005, 127, 6284-6289. 
31. Liu, Q.; Rovis, T. Asymmetric synthesis of hydrobenzofuranones via desymmetrization of cyclohexadienones using the intramolecular Stetter reaction. J. Am. Chem. Soc. 2006, 128, 2552-2553.

32. Read de Alaniz, J.; Kerr, M.S.; Moore, J.L.; Rovis, T. Scope of the asymmetric intramolecular Stetter reaction catalyzed by chiral nucleophilic triazolinylidene carbenes. J. Org. Chem. 2008, 73, 2033-2040.

33. DiRocco, D.A.; Rovis, T. Catalytic asymmetric intermolecular Stetter reaction of enals with nitroalkenes: Enhancement of catalytic efficiency through bifunctional additives. J. Am. Chem. Soc. 2011, 133, 10402-10405.

34. Jia, M.-Q.; Li, Y.; Rong, Z.-Q.; You, S.-L. Synthesis of (1R, 2R)-DPEN-derived triazolium salts and their application in asymmetric intramolecular Stetter reactions. Org. Biomol. Chem. 2011, 9, 2072-2074.

35. Moore, J.L.; Silvestri, A.P.; Read de Alaniz, J.; DiRocco, D.A.; Rovis, T. Mechanistic investigation of the enantioselective intramolecular Stetter reaction: Proton transfer is the first irreversible step. Org. Lett. 2011, 13, 1742-1745.

36. Hawkes, K.J.; Yates, B.F. The mechanism of the Stetter reaction-A DFT study. Eur. J. Org. Chem. 2008, 5563-5570.

37. He, J.; Tang, S.; Liu, J.; Su, Y.; Pan, X.; She, X. N-Heterocyclic carbene catalyzed intramolecular nucleophilic addition of carbonyl anion equivalents to enol ethers. Tetrahedron 2008, 64, 8797-8800.

38. Um, J.M.; DiRocco, D.A.; Noey, E.L.; Rovis, T.; Houk, K.N. Quantum mechanical investigation of the effect of catalyst fluorination in the intermolecular asymmetric stetter reaction. J. Am. Chem. Soc. 2011, 133, 11249-11254.

39. Domingo, L.R.; Aurell, M.J.; Arnó, M. Understanding the mechanism of the $N$-heterocyclic carbene-catalyzed ring-expansion of 4-formyl-[beta]-lactams to succinimide derivatives. Tetrahedron 2009, 65, 3432-3440.

40. Domingo, L.R.; Zaragozá, R.J.; Arnó, M. Understanding the mechanism of stereoselective synthesis of cyclopentenes via $N$-heterocyclic carbene catalyzed reactions of enals with enones. Org. Biomol. Chem. 2010, 8, 4884-4891.

41. Domingo, L.R.; Zaragozá, R.J.; Arnó, M. Understanding the cooperative NHC/LA catalysis for stereoselective annulation reactions with homoenolates. A DFT study. Org. Biomol. Chem. 2011, 9, 6616-6622.

42. Becke, A.D. Density-functional thermochemistry. III. The role of exact exchange. J. Chem. Phys. 1993, 98, 5648-5652.

43. Lee, C.; Yang, W.; Parr, R.G. Development of the Colle-Salvetti correlation-energy formula into a functional of the electron density. Phys. Rev. B 1988, 37, 785-789.

44. Hehre, W.J.; Radom, L.; Schleyer, P.V.R.; Pople, J.A. Ab initio Molecular Orbital Theory; Wiley: New York, NY, USA, 1986.

45. Schlegel, H.B. Optimization of equilibrium geometries and transition structures. J. Comput. Chem. 1982, 3, 214-218.

46. Schlegel, H.B. Advanced series in physical chemistry. In Modern Electronic Structure Theory, Yarkony, D.R., Ed.; World Scientific Publishing: Singapore, 1994; Volume 2.

47. Fukui, K. Formulation of the reaction coordinate. J. Phys. Chem. 1970, 74, 4161-4163.

48. González, C.; Schlegel, H.B. Reaction path following in mass-weighted internal coordinates. J. Phys. Chem. 1990, 94, 5523-5527. 
49. González, C.; Schlegel, H.B. Improved algorithms for reaction path following: Higher-order implicit algorithms. J. Chem. Phys. 1991, 95, 5853-5860.

50. Tomasi, J.; Persico, M. Molecular interactions in solution: An overview of methods based on continuous distributions of the solvent. Chem. Rev. 1994, 94, 2027-2094.

51. Simkin, B.Y.; Sheikhet, I. Quantum Chemical and Statistical Theory of Solutions-A Computational Approach; Ellis Horwood: London, UK, 1995.

52. Cances, E.; Mennucci, B.; Tomasi, J. A new integral equation formalism for the polarizable continuum model: Theoretical background and applications to isotropic and anisotropic dielectrics. J. Chem. Phys. 1997, 107, 3032-3041.

53. Cossi, M.; Barone, V.; Cammi, R.; Tomasi, J. Ab initio study of solvated molecules: A new implementation of the polarizable continuum model. Chem. Phys. Lett. 1996, 255, 327-335.

54. Barone, V.; Cossi, M.; Tomasi, J. Geometry optimization of molecular structures in solution by the polarizable continuum model. J. Comput. Chem. 1998, 19, 404-417.

55. Reed, A.E.; Weinstock, R.B.; Weinhold, F. Natural population analysis. J. Chem. Phys. 1985, 83, 735-746.

56. Reed, A.E.; Curtiss, L.A.; Weinhold, F. Intermolecular interactions from a natural bond orbital, donor-acceptor viewpoint. Chem. Rev. 1988, 88, 899-926.

57. Savin, A.; Becke, A.D.; Flad, J.; Nesper, R.; Preuss, H.; Vonschnering, H.G. A new look at electron localization. Angew. Chem. Int. Ed. Engl. 1991, 30, 409-412.

58. Silvi, B.; Savin, A. Classification of chemical bonds based on topological analysis of electron localization functions. Nature 1994, 371, 683-686.

59. Silvi, B. The synaptic order: A key concept to understand multicenter bonding. J. Mol. Struct. 2002, 614, 3-10.

60. Noury, S.; Krokidis, X.; Fuster, F.; Silvi, B. Computational tools for the electron localization function topological analysis. Comput. Chem. 1999, 23, 597-604.

61. Frisch M.J.; Trucks, G.W.; Schlegel, H.B.; Scuseria, G.E.; Robb, M.A.; Cheeseman, J.R.; Montgomery, J.J.A.; Vreven, T.; Kudin, K.N.; Burant, J.C.; et al. Gaussian03, Gaussian, Inc.: Wallingford, CT, USA, 2004.

62. Parr, R.G.; Pearson, R.G. Absolute hardness: Companion parameter to absolute electronegativity. J. Am. Chem. Soc. 1983, 105, 7512-7516.

63. Parr, R.G.; Yang, W. Density Functional Theory of Atoms and Molecules; Oxford University Press: New York, NY, USA, 1989.

64. Domingo, L.R.; Chamorro, E.; Pérez, P. Understanding the reactivity of captodative ethylenes in polar cycloaddition reactions. A theoretical study. J. Org. Chem. 2008, 73, 4615-4624.

65. Domingo, L.R.; Pérez, P. The nucleophilicity N index in organic chemistry. Org. Biomol. Chem. 2011, 9, 7168-7175.

66. Kohn, W.; Sham, L. Self-consistent equations including exchange and correlation effects. J. Phys. Rev. 1965, 140, 1133-1138.

67. Domingo, L.R.; Aurell, M.J.; Pérez, P.; Contreras, R. Quantitative characterization of the local electrophilicity of organic molecules. Understanding the regioselectivity on Diels-Alder reactions. J. Phys. Chem. A 2002, 106, 6871-6875.

68. Pérez, P.; Domingo, L.R.; Duque-Noreña, M.; Chamorro, E. A condensed-to-atom nucleophilicity index. An application to the director effects on the electrophilic aromatic substitutions. J. Mol. Struct. (Theochem) 2009, 895, 86-91. 
69. Parr, R.G.; Yang, W. Density functional approach to the frontier-electron theory of chemical reactivity. J. Am. Chem. Soc. 1984, 106, 4049-4050.

70. Contreras, R.; Fuentealba, P.; Galván, M.; Pérez, P. A direct evaluation of regional Fukui functions in molecules. Chem. Phys. Lett. 1999, 304, 405-413.

71. Chattaraj, P.K.; Duley, S.; Domingo L.R. Understanding local electrophilicity/nucleophilicity activation through a single reactivity difference index. Org. Biomol. Chem. 2012, in press.

72. Domingo, L.R.; Aurell, M.J.; Pérez, P.; Contreras, R. Quantitative characterization of the global electrophilicity of common diene/dienophile pairs in Diels-Alder reactions. Tetrahedron 2002, 58, 4417-4423.

73. Jaramillo, P.; Domingo, L.R.; Chamorro, E.; Pérez, P. A further exploration of a nucleophilicity index based on the gas-phase ionization potentials. J. Mol. Struct. 2008, 865, 68-72.

74. Soto-Delgado, J.; Domingo, L.R.; Contreras, R. Quantitative characterization of group electrophilicity and nucleophilicity for intramolecular Diels-Alder reactions. Org. Biomol. Chem. 2010, 8, 3678-3683.

75. Soto-Delgado, J.; Aizman, A.; Domingo, L.R.; Contreras, R. Invariance of electrophilicity of independent fragments. Application to intramolecular Diels-Alder reactions. Chem. Phys. Lett. 2010, 499, 272-277.

76. Berski, S.; Andrés, J.; Silvi, B.; Domingo, L.R. The joint use of catastrophe theory and electron localization function to characterize molecular mechanisms. A density functional study of the Diels-Alder reaction. J. Phys. Chem. A 2003, 107, 6014-6024.

77. Polo, V.; Andrés, J.; Castillo, R.; Berski, S.; Silvi, B. Understanding the molecular mechanism of the 1,3-dipolar cycloaddition between fulminic acid and acetylene in terms of the electron localization function and catastrophe theory. Chem. Eur. J. 2004, 10, 5165-5172.

78. Domingo, L.R.; Picher, M.T.; Arroyo, P.; Sáez, J.A. 1,3-Dipolar cycloadditions of electrophilically activated benzonitrile $\mathrm{N}$-oxides. Polar cycloaddition versus oxime formation. J. Org. Chem. 2006, 71, 9319-9330.

79. Berski, S.; Andrés, J.; Silvi, B.; Domingo, L.R. New findings on the Diels-Alder reactions. An analysis based on the bonding evolution theory. J. Phys. Chem. A 2006, 110, 13939-13947.

80. Polo, V.; Andrés, J.; Berski, S.; Domingo, L.R.; Silvi, B. Understanding reaction mechanisms in organic chemistry from catastrophe theory applied to the electron localization function topology. J. Phys. Chem. A 2008, 112, 7128-7136.

81. Domingo, L.R.; Chamorro, E.; Pérez, P. Understanding the high reactivity of the azomethine ylides in [3+2] cycloaddition reactions. Lett. Org. Chem. 2010, 7, 432-439.

82. Domingo, L.R.; Sáez, J.A. Understanding the electronic reorganization along the nonpolar [3+2] cycloaddition reactions of carbonyl ylides. J. Org. Chem. 2011, 76, 373-379.

Sample Availability: Cartesian coordinates of all stationary points are available from the authors.

(C) 2012 by the authors; licensee MDPI, Basel, Switzerland. This article is an open access article distributed under the terms and conditions of the Creative Commons Attribution license (http://creativecommons.org/licenses/by/3.0/). 